\title{
Prior Exposure to THC Increases the Addictive Effects of Nicotine in Rats
}

\author{
Leigh V Panlilio', Claudio Zanettini ${ }^{1,2}$, Chanel Barnes', Marcelo Solinas ${ }^{3,4}$ and Steven R Goldberg*,1 \\ 'Preclinical Pharmacology Section, Behavioral Neuroscience Research Branch, Intramural Research Program, Department of Health and Human \\ Services, National Institute on Drug Abuse, National Institutes of Health, Baltimore, MD, USA; ${ }^{2}$ Department of Pharmacology, University of Texas \\ Health Science Center, San Antonio, Texas, USA; ${ }^{3}$ Experimental and Clinical Neurosciences Laboratory, INSERM U-I 084, Poitiers, France; \\ ${ }^{4}$ University of Poitiers, Poitiers, France
}

\begin{abstract}
Although it is more common for drug abuse to progress from tobacco to cannabis, in many cases cannabis use develops before tobacco use. Epidemiological evidence indicates that prior cannabis use increases the likelihood of becoming dependent on tobacco. To determine whether this effect might be due to cannabis exposure per se, in addition to any genetic, social, or environmental factors that might contribute, we extended our series of studies on 'gateway drug' effects in animal models of drug abuse. Rats were exposed to THC, the main psychoactive constituent of cannabis, for 3 days (two intraperitoneal injections/day). Then, starting I week later, they were allowed to self-administer nicotine intravenously. THC exposure increased the likelihood of acquiring the nicotine selfadministration response from $65 \%$ in vehicle-exposed rats to $94 \%$ in THC-exposed rats. When the price of nicotine was manipulated by increasing the response requirement, THC-exposed rats maintained higher levels of intake than vehicle-exposed rats, indicating that THC exposure increased the value of nicotine reward. These results contrast sharply with our earlier findings that prior THC exposure did not increase the likelihood of rats acquiring either heroin or cocaine self-administration, nor did it increase the reward value of these drugs. The findings obtained here suggest that a history of cannabis exposure might have lasting effects that increase the risk of becoming addicted to nicotine.

Neuropsychopharmacology (2013) 38, I 198-1208; doi:10.1038/npp.2013.16; published online 6 February 2013
\end{abstract}

Keywords: self-administration; gateway drug hypothesis; behavioral economics; open field; light-dark test; cannabis

\section{INTRODUCTION}

It has long been recognized that drug abuse tends to develop with a predictable sequence, progressing from tobacco and alcohol to cannabis, and then to other drugs such as cocaine and heroin (Degenhardt et al, 2009; Kandel, 1975; Kandel et al, 1992; Siqueira and Brook, 2003; Wells and McGee, 2008). Epidemiological studies have identified several factors that might account for this progression. For example, there is evidence that using one drug not only leads to increased access to other drugs, but also makes the individual more likely to start using other drugs when they become available (Wagner and Anthony, 2002). However, it is controversial whether the typical progression arises because using certain drugs increases the likelihood of becoming addicted to other drugs, or because nonpharmacological factors predispose certain individuals to

*Correspondence: Dr SR Goldberg, Preclinical Pharmacology Section, Biomedical Research Center, National Institute on Drug Abuse, 251 Bayview Boulevard, Baltimore, MD 21224, USA, Tel: + I 4437402519 , Fax: + I 443740 2733, E-mail: sgoldber@mail.nih.gov

Received 7 September 2012; revised 20 November 2012; accepted 9 January 20 I3; accepted article preview online II January 2013 addiction in general (MacCoun, 1998, 2006; Morall et al, 2002; Vanyukov et al, 2012). Unfortunately, the correlational nature of epidemiology makes it hard to determine which factors have a causal effect, and it is particularly hard to assess the effects of drug exposure, per se, in people (Fergusson et al, 2006; Hall and Lynskey, 2005; Kandel et al, 2006; Morral et al, 2002).

In contrast, animal models of drug abuse make it relatively easy to examine the most controversial form of the 'gateway' hypothesis: that experience with one drug can predispose an individual to becoming addicted to a different drug. This hypothesis can be tested in a straightforward manner by exposing rats to one drug and later allowing them to self-administer another. If the selfadministration behavior of these rats differs from that of an unexposed control group, then this difference can be attributed to the effects of the prior drug exposure.

Research using this approach has shown that drugs can have long-lasting effects that alter subsequent responses to other drugs. For example, we have shown that a history of exposure to $\Delta 9$-tetrahydrocannabinol (THC, the active constituent of marijuana) alters the effects of heroin and cocaine. Rats that were passively exposed to THC over a 3 -day period 1 week before being offered heroin took larger 
amounts of heroin and continued to do so over many weeks of testing (Solinas et al, 2004; see also Ellgren et al, 2007). The same amount of THC exposure before being introduced to cocaine enhanced cocaine's anxiety-inducing effects and actually decreased the amount of effort that rats would expend to receive cocaine (Panlilio et al, 2007). However, neither study supported the gateway hypothesis: increased heroin intake was associated with a reduction of heroin's depressant effects rather than an enhancement of its rewarding effects, and THC exposure did not increase the likelihood that rats would initially acquire the self-administration response with either heroin or cocaine.

Tobacco is considered to be a gateway drug because its use tends to precede the use of other drugs. However, there is epidemiological evidence that cannabis use develops before tobacco use in a substantial number of cases (Agrawal et al. 2011; Tullis et al, 2003; Vaughn et al, 2008), and that cannabis use by teenagers increases the likelihood of developing tobacco dependence when they reach young adulthood (Patton et al, 2005; Timberlake et al, 2007). While there is also evidence that genetic, social, and environmental factors encourage the co-use of cannabis and tobacco (Agrawal et al, 2012), findings that cannabis use sometimes precedes regular tobacco use raise the possibility that THC exposure might increase susceptibility to nicotine addiction.

It is estimated that cigarette smoking will kill half of all lifetime users (Mackay and Eriksen, 2002). In this context, an increased risk of tobacco dependence might be the most important health consequence of cannabis use (Agrawal et al, 2008; Patton et al, 2005). Therefore, it is important to determine whether cannabis exposure per se can increase the addictive effects of nicotine. To this end, we exposed rats to THC or vehicle using the same regimen as in our previous studies (Panlilio et al, 2007; Solinas et al, 2004), then allowed them to self-administer nicotine. Since it is typical for self-administration behavior to develop in only a subset of rats that are offered nicotine, we determined whether prior exposure to THC altered the likelihood of acquiring the nicotine self-administration response. In rats that did acquire the response, we varied the dose per injection of nicotine to assess whether prior exposure to THC altered sensitivity to dose when only one response was required for each injection, and we varied the price of nicotine (ie, the number of responses required for each administration) to assess whether nicotine was more highly valued by THC-exposed rats.

\section{MATERIALS AND METHODS}

\section{Subjects}

Male Sprague-Dawley rats (Charles River, Wilmington, MA) initially weighing 275-300 $g$ were kept in temperatureand humidity-controlled conditions on a 12-h light/dark cycle. All experiments were performed during the light phase. Rats were housed two per cage until catheterization, after which they were single housed and food restricted to $\sim 15-20$ g/day. Water was freely available in the home cage. The facilities were fully accredited by the Association for Assessment and Accreditation of Laboratory Animal Care International, and all procedures were approved by the
National Institute on Drug Abuse Institutional Animal Care and Use Committee and conducted in accordance with the 2003 Guidelines of the National Research Council.

THC Pre-Exposure. Two weeks after arrival, rats were randomly assigned to two groups. THC-exposed rats received intraperitoneal (i.p.) injections of THC twice a day for 3 days, and vehicle-exposed rats received an equivalent volume of vehicle. The dose of THC was $2 \mathrm{mg} / \mathrm{kg} /$ injection on the first day, $4 \mathrm{mg} / \mathrm{kg} /$ injection on the second day, and $8 \mathrm{mg} / \mathrm{kg} /$ injection on the third day.

\section{Experiment 1: Nicotine Self-Administration}

Catheterization. One day after the last THC or vehicle injection, rats were anesthetized with ketamine $(60 \mathrm{mg} / \mathrm{kg}$, i.p.) and xylazine (10 mg/kg, i.p.), and a silastic catheter was implanted in the right jugular vein as described earlier (Panlilio and Schindler, 2000). Throughout the experiment, catheters were flushed before each daily session with $0.1 \mathrm{ml}$ of cefazolin $(82.5 \mathrm{mg} / \mathrm{ml})$ in saline solution.

Nicotine self-administration apparatus. Sound-attenuated chambers $(30 \times 24 \times 29 \mathrm{~cm}$, Coulbourn Instruments, Allentown, PA) had two nose-poke holes in the right wall. Nicotine was delivered through a fluid swivel and tubing protected by a steel spring that attached to a plastic tab between the rat's shoulders. Illumination was provided by a shielded white houselight at all times except during injection and time-out periods, when the light was pulsed at $5 \mathrm{~Hz}$. Experimental events were controlled by Med-PC (Med Associates, St Albans, VT).

Acquisition. THC-exposed and vehicle-exposed rats ( $n=17$ /group) were allowed to self-administer nicotine intravenously for 14 daily 2 -h sessions starting 1 week after catheterization. A single response (fixed ratio 1 (FR1)) in the right nose-poke hole (active hole) produced $30 \mathrm{mcg} / \mathrm{kg}$ of nicotine, a dose that is maximally effective for achieving acquisition (Donny et al, 1998; Peartree et al, 2012; Shoaib et $\mathrm{al}, 1997)$. Nicotine was delivered over $\sim 2 \mathrm{~s}$, followed by a time-out period during which further responding had no programmed consequences. Combined, the injection and timeout period lasted $5 \mathrm{~s}$. Responding in the left nose-poke hole (inactive hole) had no programmed consequences at any time. The criterion for acquisition was $\geqslant 10$ injections/ session for three consecutive sessions, the same criterion that was used in our related studies of heroin and cocaine self-administration (Panlilio et al, 2007; Solinas et al, 2004) and that has been found to be effective for identifying rats that develop stable patterns of nicotine self-administration (Mascia et al, 2011; Scherma et al, 2008; Panlilio et al, 2012). Rats that met the criterion were subsequently tested with the variable-dose or progressive-ratio procedure, and rats that completed these tests were then tested with the behavioral-economics procedure.

Variable-dose procedure. Dose-effect functions were obtained from 7 THC-exposed rats and 5 vehicle-exposed rats using a variable-dose schedule in which doses of 3 , 10,30 , and $60 \mathrm{mcg} / \mathrm{kg} /$ injection were self-administered in 
pseudorandom order (such that no dose was received more than twice in succession) throughout the 2-h session, for 3 sessions. One response was required for each injection, and dose was manipulated by varying the duration of the injection. After each injection, the latency to the next injection (including the timeout period) was recorded to measure the sensitivity of self-administration responding to changes in dose (see Gerber and Wise, 1989; Panlilio et al, 2008).

Progressive-ratio procedure. The reinforcing efficacy of various doses of nicotine was measured in nine vehicleexposed rats and ten THC-exposed rats with a progressiveratio schedule based on the procedure of Corrigall et al (2001). The response requirement started at 5 responses per injection and increased by $40 \%$ with each successive injection during a 2 -h session (values: $5,7,10,14,20,28$, $39,55,77$, and 108). Each dose of nicotine was offered for at least 3 sessions, until the injection rate varied by no more than 2 injections per session for 2 consecutive sessions; doses were tested in the order $30,10,60,3 \mathrm{mcg} / \mathrm{kg}$, after which the sequence was repeated. Since the values were comparable for the two determinations, they were averaged for analysis.

Behavioral-economics procedure. To measure the value placed on nicotine by each rat, the price of the $30 \mathrm{mcg} / \mathrm{kg}$ dose of nicotine was varied by manipulating the number of responses required for each injection (FR value). Prices of $1,2,3,5,15,30$, and 60 responses per injection were imposed for two sessions each, in ascending order; then, the sequence was repeated. Since the values were comparable for the two determinations, they were averaged for analysis. The number of injections per session was used to generate exponential demand curves for each group ( $n=6$ /group) using the procedure of Hursh and Silberberg (2008).

\section{Experiment 2: Locomotor Activity in an Open Field}

Locomotor-activity apparatus. Activity chambers (Med Associates, East Fairfield, VT, USA) were enclosed in sound-attenuation chests, with two chambers in each chest. Chambers $(41 \times 41 \times 32 \mathrm{~cm})$ were composed of clear acrylic and had sawdust bedding on the floor. Activity was measured with a $16 \times 16$ array of photobeams. Med Associates Open Field Activity Software recorded the distance traveled during the session and the number of entries into an unmarked square (defined by the software) in the center of the field ('center zone'), covering one-ninth of the total area. No illumination was provided when the chamber was closed.

Locomotor-activity procedure. To determine whether THC exposure alters the locomotor effects of nicotine, two groups were treated with THC $(n=6)$ or vehicle $(n=6)$ like in Experiment 1, ending 7 days before the start of testing in the activity chamber. During testing, all rats received nicotine $(0.4 \mathrm{mg} / \mathrm{kg}$, i.p.) immediately before being placed into the chamber for $60 \mathrm{~min}$ on each of 10 days (Monday through Friday). This dose of nicotine has been previously shown to induce locomotor sensitization when given repeatedly (Werling et al, 2009).

\section{Experiment 3: Light-Dark Test}

Light-dark test apparatus. The apparatus and procedure were described in detail by Panlilio et al (2007). Four clear acrylic shuttle boxes (MED-Associates, model ENV-010MC) were individually enclosed in sound-attenuation chests in a darkened room illuminated only by the screen of the computer. Shuttle boxes measured $40 \times 16 \times 21 \mathrm{~cm}$ and had an opaque wall $(2.5 \mathrm{~cm}$ thick) and doorway (measuring $9 \times 12 \mathrm{~cm}$ ) between the compartments, such that the lighted compartment was $20 \mathrm{~cm}$ long and the dark compartment was $17.5 \mathrm{~cm}$ long. Locomotion was measured as activity counts (ie, beam breaks), excluding consecutive, repeated breaks of the same beam.

Light-dark test procedure. The two groups of rats $(n=6$ THC exposed and 6 vehicle exposed) that were tested previously in the locomotor activity experiment were also tested 10 days later in the light-dark model of anxiety. Rats were injected with nicotine $(0.4 \mathrm{mg} / \mathrm{kg}$, i.p. $) 15 \mathrm{~min}$ before the test and remained in the darkened testing room between the injection and test. To start the test, a rat was placed in the light compartment, facing the corner of the wall with the light. Two measures were taken during the 5-min test: (1) percentage of time spent in the light compartment, not counting the time spent between the compartments and (2) the level of activity in beam breaks per minute.

\section{Drugs}

$\Delta$-9-THC (National Institute on Drug Abuse, Baltimore, $\mathrm{MD}, \mathrm{USA}$ ), $50 \mathrm{mg} / \mathrm{ml}$ in ethanol, was dissolved in a $40 \% \mathrm{w} / \mathrm{v}$ solution of cyclodextrin (RBI/SIGMA, Natick, MA) and given i.p. in a volume of $2 \mathrm{ml} / \mathrm{kg}$ (for the doses of 2 and $4 \mathrm{mg} / \mathrm{kg}$ ) or $4 \mathrm{ml} / \mathrm{kg}$ (for the $8 \mathrm{mg} / \mathrm{kg}$ dose because of solubility constraints). Ethanol concentrations in THC solutions were between 2 and $4 \%$ v/v. Corresponding amounts of ethanol were added to vehicle solutions. Nicotine ((-)-nicotine hydrogen tartrate; Sigma-Aldrich) was dissolved in saline solution ( $\mathrm{pH}$ adjusted to 7.0). Nicotine doses are expressed as free-base weight.

\section{Data Analysis}

Data were analyzed using restricted maximum likelihood estimation (Proc Mixed; SAS Institute, Cary, NC). Paired comparisons were performed using Tukey-Kramer corrections, maintaining family-wise error rates of 0.05 . For the acquisition experiment, the number of injections per session was analyzed as a function of group and session with all rats included in the analysis, and response rates (including responses during injection and timeout) were analyzed as a function of group, nose-poke hole, and session, including only rats that met the acquisition criterion; response rate data were square-root transformed to compensate for skew. Latencies under the variable-dose schedule were analyzed as a function of group and dose. For the progressive-ratio experiment, the number of injections per session was analyzed as a function of group and dose. For the behavioral economics experiment, exponential demand curves were fitted using a spreadsheet provided by Steven R. Hursh; curves were normalized to isolate the 
effect of THC exposure on the essential value placed on nicotine. Extra-sum-of-squares $\mathrm{F}$ tests comparing demand curves and comparing parameters of the curves between groups were performed using Graphpad Prism. Distance traveled and number of center-zone entries were each analyzed as a function of group, session, and time within the session. Center-zone data were excluded as outliers if they were $>10$ standard errors away from the group mean; this affected 3 sessions (2 THC-exposed rats in session 7 and one of the same THC-exposed rats in session 10).

\section{RESULTS}

\section{Experiment 1: Nicotine Self-Administration}

Acquisition. Rats exposed to THC were significantly more likely to acquire nicotine self-administration $\left(\chi_{(1)}^{2}=4.5\right.$, $p<0.034$ ), with 16 out of 17 rats in this group meeting the acquisition criterion, compared with 11 out of 17 in the control group (odds ratio $=3.1$ ). The THC-exposed group self-administered significantly more nicotine injections than the control group starting with the tenth session (Figure 1a; significant group $\times$ session interaction, $F_{(13,416)}=$ $2.04, p<0.016)$. Despite this difference in the likelihood of acquisition, THC-exposed and vehicle-exposed rats that successfully reached the criterion did so in about the same number of sessions (mean \pm SEM days to criterion: $8.1 \pm 0.7$ for THC-exposed group and $8.7 \pm 0.9$ days for the vehicleexposed group; $p>0.57$ ). Similarly, among the rats that met the criterion, response rates did not differ between the groups over the course of training (Figure 1b; significant effect of session $\times$ hole interaction, $F_{(1,25)}=2.07, p<0.015$, but not group or interactions involving group, $p$ 's $>0.17$ ), and the number of injections per session was comparable between groups on the day the criterion was met (mean \pm SEM: $14.8 \pm 1.17$ for THC-exposed rats and 13.4 \pm 1.1$)$. Among rats that failed to meet the criterion (Figure 1c), response rates were low, there was no trend toward higher rates over sessions, and there was no difference between responding in the active hole $v s$ the inactive hole.

Variable-dose and progressive-ratio schedules. Doseeffect functions for nicotine self-administration under the variable-dose schedule (Figure 2a) were quite flat compared with those obtained under comparable conditions in our related studies of heroin and cocaine self-administration. Latencies did not differ significantly as a function of dose $(p=0.16)$, and there was no significant difference between the THC- and vehicle-exposed groups under this schedule $(p=0.94)$. Dose-effect functions for nicotine under the progressive-ratio schedule (Figure $2 \mathrm{~b}$ ) were also flat and did not differ significantly as a function of either dose $(p=0.54)$ or group $(p=0.79)$.

Behavioral-economics procedure. Demand curves for nicotine (Figure 3 ) differed significantly between the two groups $\left(F_{(2,10)}=13.24, \quad p<0.0015\right)$. THC-exposed rats placed a significantly higher value on nicotine $\left(F_{(1,10)}=\right.$ $22.51, p<0.0008$ ); this is measured with $\alpha$ (the rate of change in the curve, or elasticity of demand), which was about twice as high in the vehicle-exposed group $(0.0013 v s$

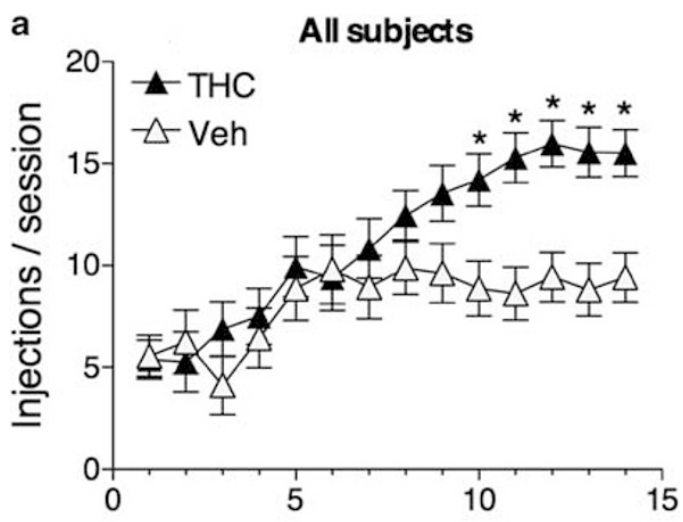

b
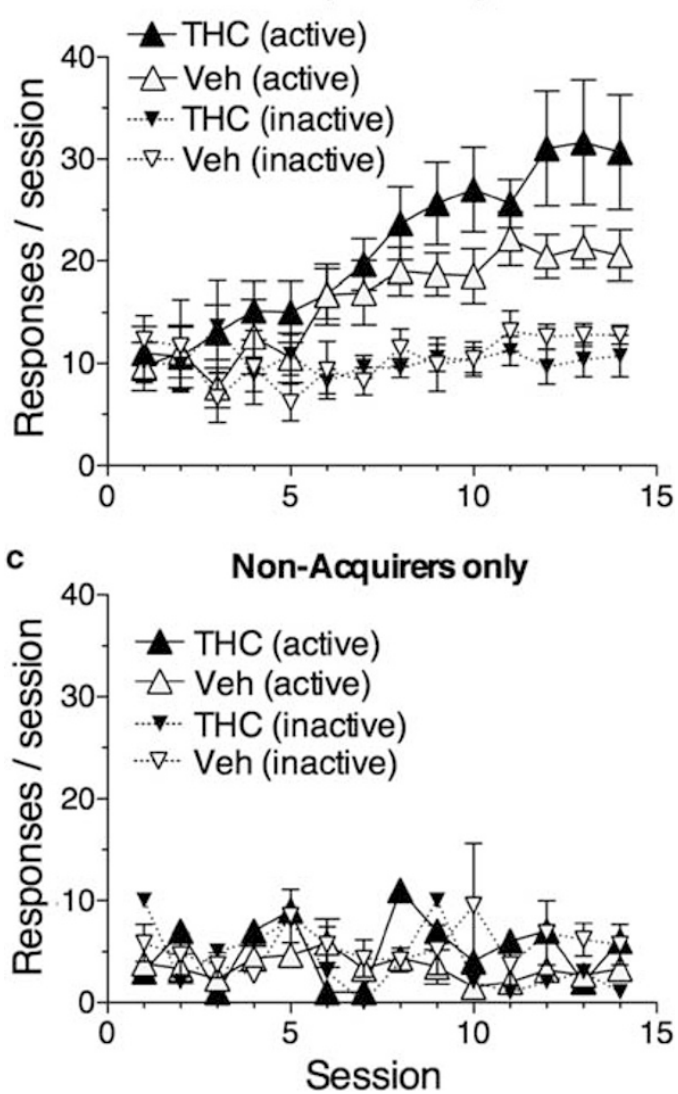

Figure I Acquisition of nicotine self-administration. (a) Rate of injection by the THC-exposed group and the vehicle-exposed control group over the course of acquisition training. This measure includes all rats trained, regardless of whether they met the acquisition criterion. Asterisks indicate that THC-exposed rats took significantly more injections per session than controls starting with the tenth session. (b) Response rates (including responses during injection and timeout) in the active and inactive nosepoke holes by rats that met the acquisition criterion of $\geqslant 10$ injections/ session for 3 consecutive sessions. Response rates did not differ significantly between groups, but paired comparisons based on the main effect of session revealed that response rates in the active hole were significantly higher than rates in the inactive hole starting with the sixth session. (c) Response rates in rats that did not meet the acquisition criterion were low, did not show an increasing trend over time, and did not differ between the active and inactive holes.

0.0007). As during acquisition, there was a tendency for THC-exposed rats to have higher rates of intake at the lowest FR requirement; however, $Q_{0}$ (the level of consumption 
at zero price) did not differ significantly between the groups $(p=0.13)$. Exponential consumption curves provided a good fit for the data, with $R^{2}$ above 0.95 for each group. Pmax, the price at which response output was maximal, was 11.4 responses/injection for the vehicleexposed group and 17.1 for the THC-exposed group.
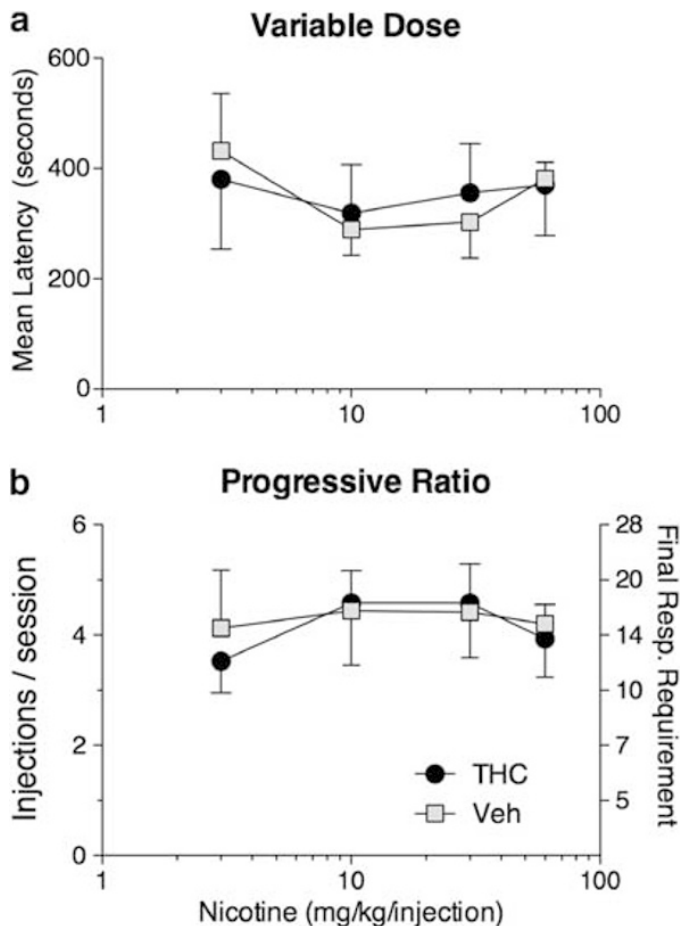

Figure 2 Effects of manipulating the dose per injection of nicotine. (a) Latencies to the next injection as a function of the previously received nicotine dose in the variable-dose schedule. (b) Rate of injection as a function of nicotine dose in the progressive-ratio schedule. Right $y$ axis shows number of responses required to obtain the number of injections indicated on the left $y$ axis. In both panels, the effect of dose was not significant, nor were there significant differences between the groups. The dose-effect functions in both panels are much flatter than the functions obtained in earlier studies with heroin (Solinas et al, 2004) and cocaine (Panlilio et al, 2007) self-administration.
Experiment 2: Locomotor Activity in an Open Field

Distance traveled. Both groups showed significant sensitization of locomotor activity, with levels increasing over the 10 days of testing with nicotine (Figures $4 \mathrm{a}$ and 5; main effect of session, $F_{(9,90)}=7.38, p<0.0001$; main effect of time within session, $\left.F_{(5,50)}=260.9, p<0.0001\right)$. Although the THC-exposed group tended to have slightly lower levels of activity than the vehicle-exposed group, this difference was not significant (main effect of group, $p=0.24$ ). Activity was highest during the first $10 \mathrm{~min}$ of each session and gradually decreased over the course of the session.

Center-zone activity. Avoiding the center of the field is considered as an indication of anxiety-like behavior. Like distance traveled, the number of center-zone entries increased over the 10 days of testing (Figures $4 \mathrm{~b}$ and 6; interaction of session and time within session, $\left.F_{(45,442)}=1.47, p<0.03\right)$. However, there were no significant differences between the groups in this measure (main effect of group, $p=0.1$ ), and there were no significant withinsubject differences related to time within the session (ie, between the time periods that made up any given session, or between the same time period compared across different sessions).

\section{Experiment 3: Light-Dark Test}

The relative amount of time spent in the light compartment was measured to assess possible anxiety-related effects of nicotine. Unlike rats treated with cocaine in our earlier study, rats treated with nicotine did not differ significantly in this measure as a function of whether they were preexposed to THC or vehicle (Figure 7; $p=0.15$ ). Consistent with the open-field test, the groups also did not differ significantly in the level of locomotor activity during the light-dark test $(p=0.18)$.

\section{DISCUSSION}

This study is part of a series designed to assess the effects of THC exposure on the subsequent use of other drugs. The main goals of this research are to determine whether a
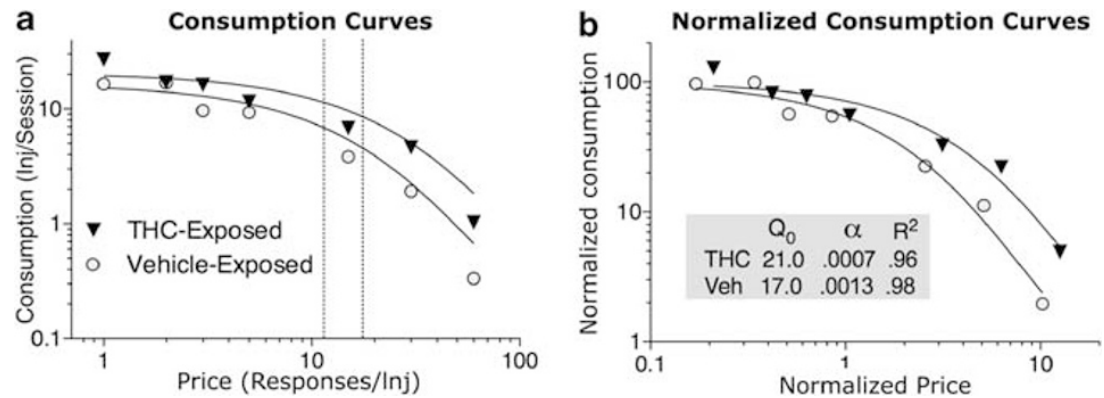

Figure 3 Demand curves from the behavioral economics experiment. THC-exposed rats placed a higher value on nicotine injections than did vehicleexposed controls. (a) Consumption curves showing number of injections per session as a function of price (ie, the number of responses required for each injection). Pmax, the price at which response output was maximal, as indicated by vertical dashed lines, was higher for the THC-exposed group. (b) Normalized consumption curves, with injections per session and price normalized to isolate differences in elasticity of demand $(\alpha)$ that were due to essential value (Hursh and Silberberg, 2008; higher $\alpha$ indicates more elasticity). Consumption is expressed as a percentage of $Q_{0}$ (consumption at price zero), and price is expressed as the fixed-ratio requirement multiplied by $Q_{0} / 100$ (ie, the number of responses required to consume $1 \%$ of the level consumed at price zero). Goodness of fit $\left(R^{2}\right)$ for the regressed functions was high for both groups. 
history of cannabinoid exposure: (1) increases the likelihood that other drugs will be self-administered on a regular basis and (2) increases the reinforcing efficacy of these drugs such that self-administration becomes highly persistent. The first question is addressed by determining the percentage of rats that acquire the self-administration response when a drug is offered. The second question is addressed by determining the extent to which self-administration behavior is sustained when the effort required to
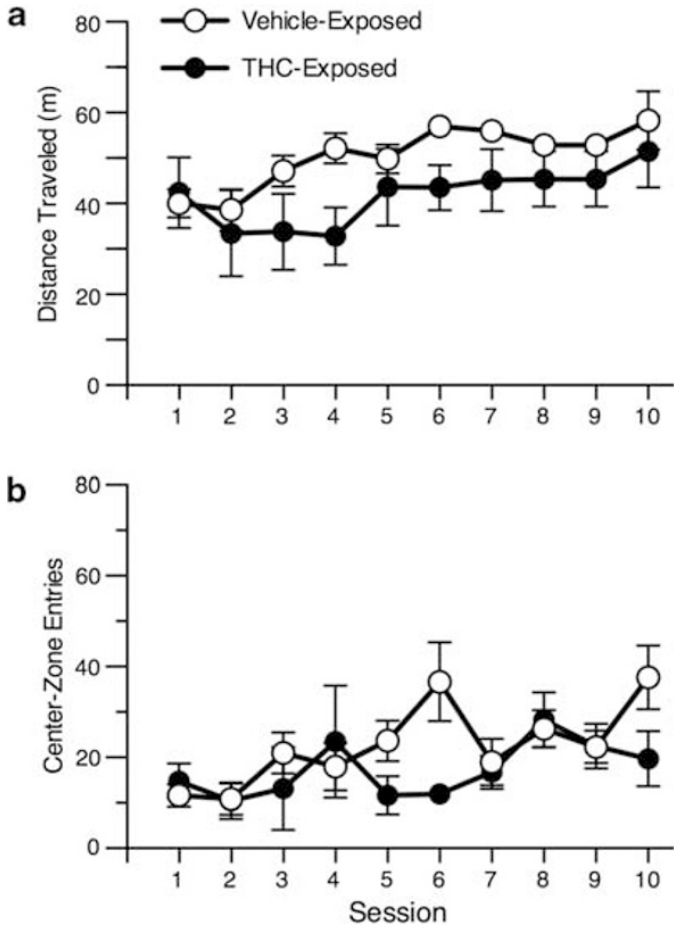

Figure 4 Locomotor activity in an open field. (a) Distance traveled, a measure of forward locomotion. (b) Center-zone entries, a measure of anxiety-related behavior, with higher values indicating lower anxiety. All rats received an intraperitoneal nicotine injection before each session. There were no significant differences between the THC-exposed and vehicleexposed groups for either measure. Paired comparisons for the main effect of session revealed that distance traveled was significantly higher in sessions 9 and 10 compared with sessions 1, 2, 3, and 4, and in sessions 6, 7, and 8 compared with session 2. Center-zone entries were significantly higher in session 10 compared with session 2 and in session 8 compared with sessions I and 2 . obtain the drug (ie, the price) is increased in progressiveratio and behavioral economics procedures.

The most striking finding of the present study is that THC-exposed rats were more likely than controls to acquire the nicotine self-administration response. This finding differs from our earlier studies, in which a history of THC exposure did not alter the likelihood that rats would acquire a heroin (Solinas et al, 2004) or cocaine (Panlilio et al, 2007) self-administration response. In those studies, the percentage of rats that met the criterion for acquiring the heroin or cocaine self-administration response was about $80 \%$ regardless of whether they had been exposed to THC or vehicle. In contrast, the percentage of rats that acquired the nicotine self-administration response in the present study was $94 \%$ in the THC-exposed group and only $65 \%$ in the vehicle-exposed group. This finding is consistent with epidemiological evidence that prior cannabis use increases the likelihood of becoming dependent on tobacco (Patton et al, 2005; Timberlake et al, 2007).

Regarding the question of whether THC exposure would alter the reinforcing efficacy of nicotine and make nicotine self-administration more persistent, our findings were again consistent with epidemiological data and again substantially different from our findings with heroin and cocaine. In the earlier studies, we found that THC-exposed rats did not differ from vehicle-exposed rats in their consumption of heroin when the price was increased, but THC-exposed rats were actually less persistent than controls in self-administering cocaine, reducing consumption more readily than controls when the price was increased. In contrast, in the behavioral economics test of the present study, we found that nicotine self-administration was more persistent in THC-exposed rats; as the price was raised, the drop in consumption was twice as steep in the vehicle-exposed group. This finding indicates that THC-exposed rats placed a higher value on nicotine (Hursh and Silberberg, 2008) and devoted more time and energy to acquire the drug, effects analogous to the Diagnostic and Statistical Manual (4th edition) criteria for drug dependence.

Although clear group differences were observed with the acquisition and behavioral-economics procedures, group differences were not detected in the progressive-ratio or variable-dose procedures. In fact, the curves in both of these experiments were flat, with no significant dose-related changes within either group. The flatness of dose-effect curves obtained with FR schedules of nicotine

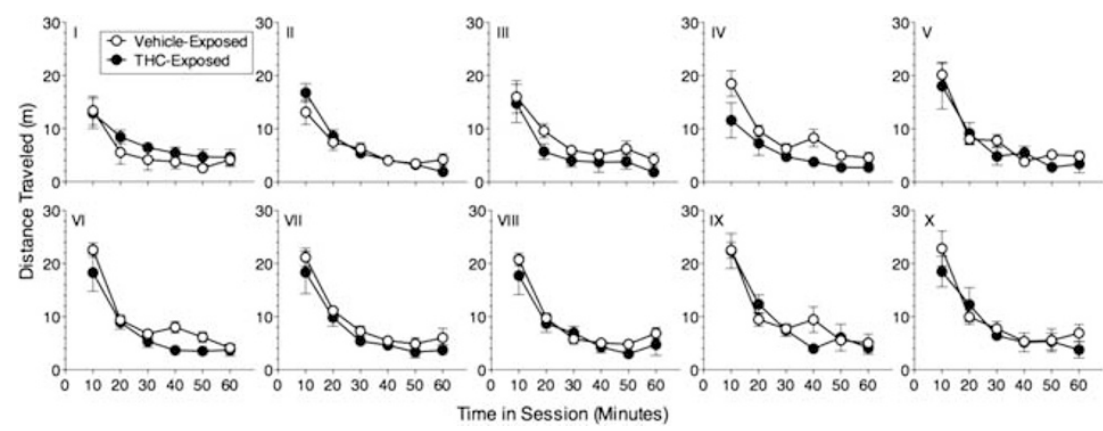

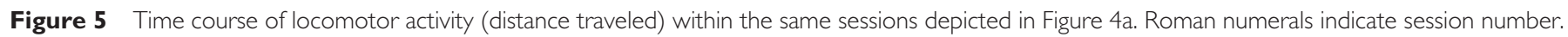

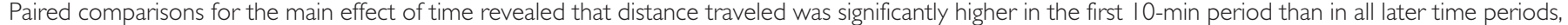
higher in the second 10-min period than in all later time periods, and higher during the third I0-min period than in the fifth and sixth time periods. 

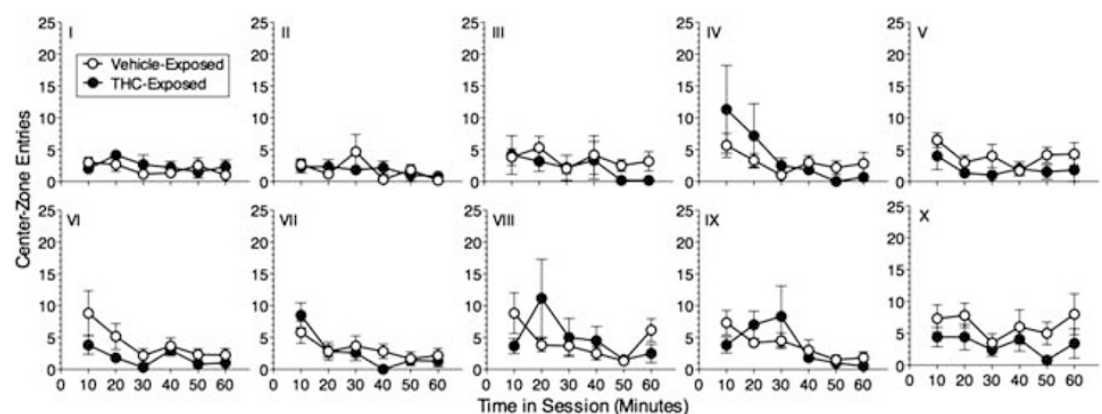

Figure 6 Time course of locomotor activity (center-zone entries) within the same sessions depicted in Figure 4b. Roman numerals indicate session number. There were no significant differences over time for this measure.

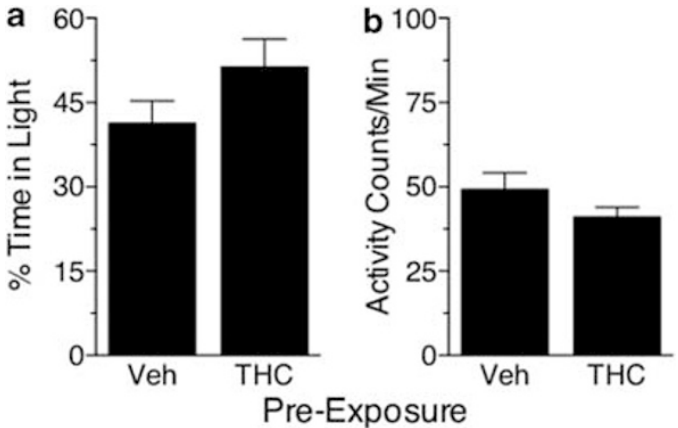

Figure 7 Results from the light-dark model of anxiety in rats preexposed to THC or vehicle ('Veh') and treated with nicotine $(0.4 \mathrm{mg} / \mathrm{kg}$, i.p.) $15 \mathrm{~min}$ before the test. (a) Percentage of time spent in the light compartment. Higher values indicate less anxiety. (b) Locomotor activity (counts/min) during the same test. The groups did not differ significantly in either time allocation or general level of activity.

self-administration has been observed repeatedly, leading to suggestions that intake of nicotine might be regulated by a different mechanism than other drugs (Corrigall, 1991; Corrigall et al, 2001; Palmatier et al, 2007). Dose-effect curves obtained with progressive-ratio schedules of nicotine self-administration have been found to be steeper than those obtained with FR schedules, but still flatter than those typically obtained with heroin or cocaine (Bruijnzeel and Markou, 2003; Freeman and Woolverton, 2009; Gould et al, 2011; Risner and Goldberg, 1983). As a whole, these findings suggest that nicotine dose has a relatively small influence on self-administration behavior. Notably, a major difference between the progressive-ratio and behavioral economics procedures used here is that both the dose and the response requirement were varied in the progressive-ratio schedule, but only the response requirement was varied in the behavioral-economics procedure. As a consequence, the progressive-ratio procedure used here might have been less sensitive than the behavioral-economics procedure as a measure of changes in the reinforcing efficacy of nicotine.

A caveat to the progressive-ratio experiment is that injection rates were lower than in earlier studies on which the present procedure was modeled (Coen et al, 2009; Corrigall et al, 2001; Ross et al, 2007), raising the possibility that a floor or ceiling effect might have obscured differences between the THC-exposed and vehicle-exposed groups. However, the highest response requirement reached in the progressive-ratio experiment (about 16 responses/injection in both groups) was comparable to the Pmax values in the behavioral economics experiment (11.4 and 17.1 responses/ injection for the vehicle-exposed and THC-exposed groups, respectively), in which behavior was found to be sensitive to price and to differ between groups. In the case of the variable-dose experiment, it is possible that substantially different curves would be obtained if the same doses were tested with a fixed-dose schedule. However, it should be noted that fixed-dose and variable-dose curves were nearly identical to each other in earlier studies with heroin, cocaine, and remifentanil self-administration (Panlilio and Schindler, 2000, 2007; Solinas et al, 2004; see also Gerber and Wise, 1989).

In our previous studies of THC exposure (Panlilio et al, 2007; Solinas et al, 2004), the open-field and light-dark tests provided information that was complementary to the main findings obtained with drug self-administration. Consistent with a previous study of the locomotor effects of morphine (Cadoni et al, 2001), the open-field test indicated that a history of THC exposure decreased the duration of heroin's depressant locomotor effects (Panlilio et al, 2007). This cross-tolerance to opioids' locomotor effects could explain why THC-exposed rats consumed larger amounts of heroin than vehicle-exposed rats when the price of heroin was low; they may have recovered from heroin's effects sooner after each injection, allowing them to take more injections per session. In open-field testing, analysis of center-zone entries revealed that THC-exposed rats exhibited thigmotaxis, an anxiety-like avoidance of the center of the field, when they were given cocaine. This finding was further supported by testing with cocaine in the light-dark model of anxiety. In the open-field test of the present study, there were no significant differences between the THC-exposed and vehicle-exposed groups in either locomotor activity or center-zone entries during 10 days of testing with intraperitoneal nicotine. Similarly, THC exposure did not alter behavior in the light-dark model of anxiety when the rats were given nicotine. Although there were no control groups that did not receive nicotine in these experiments, we found in three previous experiments that the THC-exposure regimen used here did not alter locomotor activity or anxiety-like behavior in rats that were given only saline solution during the test (Panlilio et al, 2007). Thus, the finding that THC-exposed and vehicle-exposed rats did not differ from each other when given nicotine in the open-field and light-dark tests suggests that the group differences observed in the acquisition and behavioral economics 
experiments were not due to changes in the locomotor or anxiety-related effects of nicotine.

Since only a subset of people who try tobacco become habitual users, it is important to learn what factors influence this progression. Nicotine generally has weaker reinforcing effects than heroin or cocaine (Chaudhri et al, 2007; Le Foll and Goldberg, 2009; Mello and Newman, 2011); for example, as mentioned above, only $65 \%$ of the control rats in the present nicotine study acquired the selfadministration response, compared with about $80 \%$ in our parallel studies with heroin or cocaine. However, once nicotine use is established, it can become highly persistent. Addicted humans (Harvey et al, 2004) and animals Le Foll and Goldberg, 2009 will expend substantial amounts of effort to consume nicotine, and most smokers who try to quit are unsuccessful (Stapleton, 1998). These facts, combined with the enormity of tobacco's adverse health effects, lend weight to the findings obtained here that suggest cannabis use might increase the odds of a person becoming both a regular tobacco smoker and a highly persistent tobacco smoker.

These findings extend the results of other studies showing that previous exposure to caffeine or nicotine itself can alter the likelihood of acquiring nicotine self-administration behavior. Rats that were passively exposed to nicotine $(0.4 \mathrm{mg} / \mathrm{kg}$ s.c. $)$ in the home cage subsequently acquired a nicotine self-administration response slightly more rapidly than non-exposed rats (Shoaib et al, 1997). Rats that were exposed to caffeine in their drinking water were more likely to acquire the nicotine self-administration response, acquired this behavior more rapidly, and took larger amounts of nicotine than rats that never received caffeine (Shoaib et al, 1999); but, since caffeine exposure was maintained both before and during the acquisition training in this study, it is not known how much these effects were due to a history of caffeine exposure, as opposed to having caffeine in the system at the same time as nicotine. Preexposure to nicotine in post-adolescent rats produced a tolerance-like effect, preventing the development of conditioned place preference when a distinctive environment was associated with $0.3 \mathrm{mg} / \mathrm{kg}$ nicotine, but not a higher dose $(0.6 \mathrm{mg} / \mathrm{kg}$; Adriani et al, 2006).

There is much evidence that acute or ongoing treatment with cannabinoid receptor ligands can modulate the effects of nicotine (Castañé et al, 2005; Solinas et al, 2008). Cannabinoid antagonists such as rimonabant reduce the reward-related effects of nicotine in behavioral and neurochemical procedures in animals (Cohen et al, 2002; Forget et al, 2005; Le Foll and Goldberg, 2004; Shoaib, 2008) and increase the odds of smoking cessation in humans (Cahill and Ussher 2007; Le Foll et al, 2008, 2009; Rigotti et al, 2009). Furthermore, cannabinoid agonists have the opposite effect, enhancing the rewarding effects of nicotine and reinstating nicotine seeking in rats (Gamaleddin et al, 2012). Further evidence of crosstalk between cannabinoids and nicotine comes from studies showing that nicotine can facilitate many of the acute pharmacological and biochemical effects of THC, including reward, anxiolysis, tolerance, and physical dependence (Valjent et al, 2002; Viveros et al, 2006).

Other studies have identified lasting effects on the brain after relatively brief cannabinoid exposure. Adolescent cannabis users have lower levels of glutamate and $\mathrm{N}$-acetyl aspartate in the anterior cingulate cortex (Prescot et al, 2011), and they show cognitive deficits (Schweinsburg et al, 2008) and changes in global and regional cerebral blood flow (Martín-Santos et al, 2010) that have been detected up to 6 weeks after exposure. In animals, subchronic THC exposure can decrease the density and expression of cannabinoid $\mathrm{CB}_{1}$ receptors in many areas of the brain, and pharmacodynamic changes such as these underlie tolerance to cannabinoids (Maldonado, 2002). Behavioral sensitization induced by repeated acute exposure to cannabinoid agonists is associated with increased intracellular activation of $\mathrm{CB}_{1}$ receptors in the caudate putamen and cerebellum (Rubino et al, 2003; see also Rubino et al, 2004), increased $\mu$-opioid receptor binding in the lateral thalamus and periaqueductal gray (PAG), and increased intracellular activation of $\mu$-opioid receptors in the nucleus accumbens (Viganò et al, 2005). Using a THC pre-exposure regimen that increases heroin intake in rats under an FR1 schedule, Ellgren et al $(2007,2008)$ found lasting alterations of both the cannabinoid and opioid systems in rats exposed to THC during adolescence. These changes were most prominent in the nucleus accumbens, which has a key role in the rewarding effects of nicotine and other addictive drugs (Corrigall et al, 1992; Maskos et al, 2005). Since opioid receptors have been implicated in nicotine reward, tolerance, and withdrawal (Berrendero et al, 2010; Hadjiconstantino and Neff, 2011), these findings suggest that the effects observed in the present study might be due to an interaction between the cannabinoid, opioid, and nicotinic-acetylcholine systems.

There are genetic, social, and environmental factors that encourage the use of both cannabis and tobacco by the same individual (Agrawal et al, 2012). A possible explanation for gateway-like progressions from one drug to others is transfer of learning, in which established drug-seeking behavior comes to be reinforced by the effects of a different drug. This kind of effect seems likely in the case of cannabis and tobacco due to shared features of the behavioral chains involved in smoking these substances (Lee et al, 2010). However, the gateway-like effect observed in the present study did not involve transfer of learning, since the rats received THC passively. It should also be noted that rats did not receive THC and nicotine simultaneously in the present study, but that the results might still be relevant to simultaneous use. Tobacco and cannabis are often coadministered because users believe that nicotine potentiates the effects of cannabis (Amos et al, 2004; Lee et al, 2010). Such co-administration could encourage a progression from cannabis to tobacco by a number of mechanisms. To the extent that cannabis is the primary drug of abuse in these cases, these mechanisms might include the gateway-like effect observed here.

Many of the demographic factors that are associated with dependence on one drug are also associated with dependence on other drugs (Anthony et al, 1994). A commonfactor model -in which users progress from one drug to another because of a general susceptibility to drug dependence-could potentially explain the progression from one drug to another as different drugs become available (MacCoun, 1998, 2006; Morall et al, 2002; Tarter et al, 2006; Vanyukov et al, 2012). However, there is 
epidemiological evidence for gateway effects even when such factors are controlled (Agrawal et al, 2008; Fergusson et al, 2006), and findings with animal models support the possibility that exposure to cannabis can alter the abuserelated effects of other drugs (Cadoni et al, 2001; Ellgren et al, 2007; Panlilio et al, 2007; Solinas et al, 2004). Since there is evidence for both common-factor effects and lasting effects of drug exposure per se, and since these explanations are not mutually exclusive, it seems likely that both types of effect can occur and that they may in fact build upon each other.

\section{Conclusion}

Nicotine is the first drug we have tested that was more likely to be self-administered by subjects with a history of being exposed to THC than by control subjects exposed to vehicle. Nicotine is also the first drug we have tested that was selfadministered more persistently by THC-exposed subjects than controls when the price was increased. Both of these findings are consistent with a gateway hypothesis in which prior use of cannabis facilitates a progression to tobacco dependence. While there are many factors that might contribute to such a progression, the present study suggests that lasting effects of THC exposure per se make cannabis users more susceptible to the addictive effects of tobacco.

\section{ACKNOWLEDGEMENTS}

This research was supported by the Intramural Research Program of the NIH, National Institute on Drug Abuse. Thanks to Syrena Bracey for assistance in conducting the experiments.

\section{DISCLOSURE}

The authors declare no conflict of interest.

\section{REFERENCES}

Adriani W, Deroche-Gamonet V, Le Moal M, Laviola G, Piazza PV (2006). Preexposure during or following adolescence differently affects nicotine-rewarding properties in adult rats. Psychopharmacology (Berl) 184: 382-390.

Agrawal A, Budney AJ, Lynskey MT (2012). The co-occurring use and misuse of cannabis and tobacco: a review. Addiction 107: 1221-1233.

Agrawal A, Madden PA, Bucholz KK, Heath AC, Lynskey MT (2008). Transitions to regular smoking and to nicotine dependence in women using cannabis. Drug Alcohol Depend 95: $107-114$

Agrawal A, Scherrer JF, Lynskey MT, Sartor CE, Grant JD, Haber JR et al (2011). Patterns of use, sequence of onsets and correlates of tobacco and cannabis. Addict Behav 36: 1141-1147.

Amos A, Wiltshire S, Bostock Y, Haw S, McNeill A (2004). 'You can't go without a fag. you need it for your hash'-a qualitative exploration of smoking, cannabis and young people. Addiction 99: 77-81.

Anthony JC, Warner LA, Kessler RC (1994). Comparative epidemiology of dependence on tobacco, alcohol, controlled substances, and inhalants: basic findings from the national comorbidity survey. Exp Clin Psychopharmacol 2: 244-268.
Berrendero F, Robledo P, Trigo JM, Martín-García E, Maldonado R (2010). Neurobiological mechanisms involved in nicotine dependence and reward: participation of the endogenous opioid system. Neurosci Biobehav Rev 35: 220-231.

Bruijnzeel AW, Markou A (2003). Characterization of the effects of bupropion on the reinforcing properties of nicotine and food in rats. Synapse 50: 20-28.

Cadoni C, Pisanu A, Solinas M, Acquas E, Di Chiara G (2001). Behavioural sensitization after repeated exposure to Delta 9-tetrahydrocannabinol and cross-sensitization with morphine. Psychopharmacology (Berl) 158: 259-266.

Cahill K, Ussher M (2007). Cannabinoid type 1 receptor antagonists (rimonabant) for smoking cessation. Cochrane Database Syst Rev 2007: CD005353.

Castañé A, Berrendero F, Maldonado R (2005). The role of the cannabinoid system in nicotine addiction. Pharmacol Biochem Behav 81: 381-386.

Chaudhri N, Caggiula AR, Donny EC, Booth S, Gharib M, Craven L et al (2007). Self-administered and noncontingent nicotine enhance reinforced operant responding in rats: impact of nicotine dose and reinforcement schedule. Psychopharmacology (Berl) 190: 353-362.

CIRRUS Study Group. Rigotti NA, Gonzales D, Dale LC, Lawrence D, Chang Y (2009). A randomized controlled trial of adding the nicotine patch to rimonabant for smoking cessation: efficacy, safety and weight gain. Addiction 104: 266-276.

Coen KM, Adamson KL, Corrigall WA (2009). Medication-related pharmacological manipulations of nicotine self-administration in the rat maintained on fixed- and progressive-ratio schedules of reinforcement. Psychopharmacology (Berl) 201: 557-568.

Cohen C, Perrault G, Voltz C, Steinberg R, Soubrie P (2002). SR141716, a central cannabinoid $(\mathrm{CB}(1))$ receptor antagonist, blocks the motivational and dopamine-releasing effects of nicotine in rats. Behav Pharmacol 13: 451-463.

Corrigall WA (1991). A rodent model for nicotine self-administration. In: Boulton A, Baker GB, Wu PH (eds). Animal Models of Drug Addiction. Neuromethods Vol 21 (Humana: Clifton, NJ), pp 315-344.

Corrigall WA, Coen KM, Zhang J, Adamson KL (2001). GABA mechanisms in the pedunculopontine tegmental nucleus influence particular aspects of nicotine self-administration selectively in the rat. Psychopharmacology (Berl) 158: 190-197.

Corrigall WA, Franklin KB, Coen KM, Clarke PB (1992). The mesolimbic dopaminergic system is implicated in the reinforcing effects of nicotine. Psychopharmacology (Berl) 107: 285-289.

Degenhardt L, Chiu WT, Conway K, Dierker L, Glantz M, Kalaydjian A et al (2009). Does the 'gateway' matter? Associations between the order of drug use initiation and the development of drug dependence in the National Comorbidity Study Replication. Psychol Med 39: 157-167.

Donny EC, Caggiula AR, Mielke MM, Jacobs KS, Rose C, Sved AF (1998). Acquisition of nicotine self-administration in rats: the effects of dose, feeding schedule, and drug contingency. Psychopharmacology (Berl) 136: 83-90.

Ellgren M, Artmann A, Tkalych O, Gupta A, Hansen HS, Hansen $\mathrm{SH}$ et al (2008). Dynamic changes of the endogenous cannabinoid and opioid mesocorticolimbic systems during adolescence: THC effects. Eur Neuropsychopharmacol 18: 826-834.

Ellgren M, Spano SM, Hurd YL (2007). Adolescent cannabis exposure alters opiate intake and opioid limbic neuronal populations in adult rats. Neuropsychopharmacology 32: 607-615.

Fergusson DM, Boden JM, Horwood LJ (2006). Cannabis use and other illicit drug use: testing the cannabis gateway hypothesis. Addiction 101: 556-569.

Forget B, Hamon M, Thiebot MH (2005). Cannabinoid CB1 receptors are involved in motivational effects of nicotine in rats. Psychopharmacology (Berl) 181: 722-734. 
Freeman KB, Woolverton WL (2009). Self-administration of cocaine and nicotine mixtures by rhesus monkeys. Psychopharmacology (Berl) 207: 99-106.

Gamaleddin I, Wertheim C, Zhu AZ, Coen KM, Vemuri K, Makryannis A et al (2012). Cannabinoid receptor stimulation increases motivation for nicotine and nicotine seeking. Addict Biol 17: 47-61.

Gerber GJ, Wise RA (1989). Pharmacological regulation of intravenous cocaine and heroin self-administration in rats: a variable dose paradigm. Pharmacol Biochem Behav 32: 527-531.

Gould RW, Czoty PW, Nader SH, Nader MA (2011). Effects of varenicline on the reinforcing and discriminative stimulus effects of cocaine in rhesus monkeys. J Pharmacol Exp Ther 339: 678-686.

Hadjiconstantinou M, Neff NH (2011). Nicotine and endogenous opioids: neurochemical and pharmacological evidence. Neuropharmacology 60: 1209-1220.

Hall WD, Lynskey M (2005). Is cannabis a gateway drug? Testing hypotheses about the relationship between cannabis use and the use of other illicit drugs. Drug Alcohol Rev 24: 39-48.

Harvey DM, Yasar S, Heishman SJ, Panlilio LV, Henningfield JE, Goldberg SR (2004). Nicotine serves as an effective reinforcer of intravenous drug-taking behavior in human cigarette smokers. Psychopharmacology (Berl) 175: 134-142.

Hursh SR, Silberberg A (2008). Economic demand and essential value. Psychol Rev 115: 186-198.

Kandel DB (1975). Stages in adolescent involvement in drug use. Science 190: 912-914.

Kandel DB, Yamaguchi K, Chen K (1992). Stages of progression in drug involvement from adolescence to adulthood: further evidence for the gateway theory. J Stud Alcohol 53: 447-457.

Kandel DB, Yamaguchi K, Klein LC (2006). Testing the gateway hypothesis. Addiction 101: 470-472.

Le Foll B, Forget B, Aubin HJ, Goldberg SR (2008). Blocking cannabinoid CB1 receptors for the treatment of nicotine dependence: insights from pre-clinical and clinical studies. Addict Biol 13: 239-252.

Le Foll B, Goldberg SR (2004). Rimonabant, a CB1 antagonist, blocks nicotine-conditioned place preferences. Neuroreport 15: 2139-2143.

Le Foll B, Goldberg SR (2009). Effects of nicotine in experimental animals and humans: an update on addictive properties. Handb Exp Pharmacol 192: 335-367.

Lee JP, Battle RS, Lipton R, Soller B (2010). 'Smoking': use of cigarettes, cigars and blunts among Southeast Asian American youth and young adults. Health Educ Res 25: 83-96.

MacCoun R (1998). In what sense (if any) is marijuana a gateway drug? Drug Policy Anal Bull 4: 5-8.

MacCoun RJ (2006). Competing accounts of the gateway effect: the field thins, but still no clear winner. Addiction 101: 473-474.

Mackay J, Eriksen M (2002). The Tobacco Atlas. World Health Organization: Geneva.

Maldonado R (2002). Study of cannabinoid dependence in animals. Pharmacol Ther 95: 153-164.

Martín-Santos R, Fagundo AB, Crippa JA, Atakan Z, Bhattacharyya $\mathrm{S}$, Allen $\mathrm{P}$ et al (2010). Neuroimaging in cannabis use: a systematic review of the literature. Psychol Med 40: 383-398.

Mascia P, Pistis M, Justinova Z, Panlilio LV, Luchicchi A, Lecca S et al (2011). Blockade of nicotine reward and reinstatement by activation of alpha-type peroxisome proliferator-activated receptors. Biol Psychiatry 69: 633-641.

Maskos U, Molles BE, Pons S, Besson M, Guiard BP, Guilloux JP et al (2005). Nicotine reinforcement and cognition restored by targeted expression of nicotinic receptors. Nature 436: 103-107.

Mello NK, Newman JL (2011). Discriminative and reinforcing stimulus effects of nicotine, cocaine, and cocaine + nicotine combinations in Rhesus Monkeys. Exp Clin Psychopharmacol 19: 203-214.
Morral AR, McCaffrey DF, Paddock SM (2002). Reassessing the marijuana gateway effect. Addiction 97: 1493-1504.

Palmatier MI, Liu X, Caggiula AR, Donny EC, Sved AF (2007). The role of nicotinic acetylcholine receptors in the primary reinforcing and reinforcement-enhancing effects of nicotine. Neuropsychopharmacology 32: 1098-1108.

Panlilio LV, Justinova Z, Mascia P, Pistis M, Luchicchi A, Lecca S et al (2012). Novel use of a lipid-lowering fibrate medication to prevent nicotine reward and relapse: preclinical findings. Neuropsychopharmacology 37: 1838-1847.

Panlilio LV, Schindler CW (2000). Self-administration of remifentanil, an ultra-short acting opioid, under continuous and progressive-ratio schedules of reinforcement in rats. Psychopharmacology (Berl) 150: 61-66.

Panlilio LV, Solinas M, Matthews SA, Goldberg SR (2007). Previous exposure to THC alters the reinforcing efficacy and anxietyrelated effects of cocaine in rats. Neuropsychopharmacology 32: 646-657.

Panlilio LV, Thorndike EB, Schindler CW (2008). A stimuluscontrol account of regulated drug intake in rats. Psychopharmacology (Berl) 196: 441-450.

Patton GC, Coffey C, Carlin JB, Sawyer SM, Lynskey M (2005). Reverse gateways? Frequent cannabis use as a predictor of tobacco initiation and nicotine dependence. Addiction 100: $1518-1525$

Peartree NA, Sanabria F, Thiel KJ, Weber SM, Cheung TH, Neisewander JL (2012). A new criterion for acquisition of nicotine self-administration in rats. Drug Alcohol Depend 124: 63-69.

Prescot AP, Locatelli AE, Renshaw PF, Yurgelun-Todd DA (2011). Neurochemical alterations in adolescent chronic marijuana smokers: a proton MRS study. Neuroimage 57: 69-75.

Risner ME, Goldberg SR (1983). A comparison of nicotine and cocaine self-administration in the dog: fixed-ratio and progressive-ratio schedules of intravenous drug infusion. J Pharmacol Exp Ther 224: 319-326.

Ross JT, Corrigall WA, Heidbreder CA, LeSage MG (2007). Effects of the selective dopamine D3 receptor antagonist SB-277011A on the reinforcing effects of nicotine as measured by a progressive-ratio schedule in rats. Eur J Pharmacol 559: 173-179.

Rubino T, Forlani G, Viganò D, Zippel R, Parolaro D (2004). Modulation of extracellular signal-regulated kinases cascade by chronic delta 9-tetrahydrocannabinol treatment. Mol Cell Neurosci 25: 355-362.

Rubino T, Viganò D, Massi P, Parolaro D (2003). Cellular mechanisms of Delta 9-tetrahydrocannabinol behavioural sensitization. Eur J Neurosci 17: 325-330.

Scherma M, Panlilio LV, Fadda P, Fattore L, Gamaleddin I, Le Foll $B$ et al (2008). Inhibition of anandamide hydrolysis by cyclohexyl carbamic acid 3'-carbamoyl-3-yl ester (URB597) reverses abuse-related behavioral and neurochemical effects of nicotine in rats. J Pharmacol Exp Ther 327: 482-490.

Schweinsburg AD, Brown SA, Tapert SF (2008). The influence of marijuana use on neurocognitive functioning in adolescents. Curr Drug Abuse Rev 1: 99-111.

Shoaib M (2008). The cannabinoid antagonist AM251 attenuates nicotine self-administration and nicotine-seeking behaviour in rats. Neuropharmacology 52: 438-444.

Shoaib M, Schindler CW, Goldberg SR (1997). Nicotine selfadministration in rats: strain and nicotine pre-exposure effects on acquisition. Psychopharmacology (Berl) 129: 35-43.

Shoaib M, Swanner LS, Yasar S, Goldberg SR (1999). Chronic caffeine exposure potentiates nicotine self-administration in rats. Psychopharmacology (Berl) 142: 327-333.

Siqueira LM, Brook JS (2003). Tobacco use as a predictor of illicit drug use and drug-related problems in Colombian youth. J Adolesc Health 32: 50-57. 
Solinas M, Goldberg SR, Piomelli D (2008). The endocannabinoid system in brain reward processes. Br J Pharmacol 154: 369-383.

Solinas M, Panlilio LV, Goldberg SR (2004). Exposure to delta-9tetrahydrocannabinol (THC) increases subsequent heroin taking but not heroin's reinforcing efficacy: a self-administration study in rats. Neuropsychopharmacology 29: 1301-1311.

Stapleton J (1998). Cigarette smoking prevalence, cessation and relapse. Stat Methods Med Res 7: 187-203.

Tarter RE, Vanyukov M, Kirisci L, Reynolds M, Clark DB (2006). Predictors of marijuana use in adolescents before and after licit drug use: examination of the gateway hypothesis. Am J Psychiatry 163: 2134-2140.

Timberlake DS, Haberstick BC, Hopfer CJ, Bricker J, Sakai JT, Lessem JM et al (2007). Progression from marijuana use to daily smoking and nicotine dependence in a national sample of U.S. adolescents. Drug Alcohol Depend 88: 272-281.

Tullis LM, Dupont R, Frost-Pineda K, Gold MS (2003). Marijuana and tobacco: a major connection? J Addict Dis 22: 51-62.

Valjent E, Mitchell JM, Besson MJ, Caboche J, Maldonado R (2002). Behavioural and biochemical evidence for interactions between Delta 9-tetrahydrocannabinol and nicotine. Br J Pharmacol 135: 564-578.

Vanyukov MM, Tarter RE, Kirillova GP, Kirisci L, Reynolds MD, Kreek MJ et al (2012). Common liability to addiction and 'gateway hypothesis': theoretical, empirical and evolutionary perspective. Drug Alcohol Depend 123: S3-S17.

Vaughn M, Wallace J, Perron B, Copeland V, Howard M (2008). Does marijuana use serve as a gateway to cigarette use for high-risk African-American youth? Am J Drug Alcohol Abuse 34: 782-791.

Viganò D, Rubino T, Vaccani A, Bianchessi S, Marmorato P, Castiglioni $\mathrm{C}$ et al (2005). Molecular mechanisms involved in the asymmetric interaction between cannabinoid and opioid systems. Psychopharmacology (Berl) 182: 527-536.

Viveros MP, Marco EM, File SE (2006). Nicotine and cannabinoids: parallels, contrasts and interactions. Neurosci Biobehav Rev 30: 1161-1181.

Wagner FA, Anthony JC (2002). Into the world of illegal drug use: exposure opportunity and other mechanisms linking the use of alcohol, tobacco, marijuana, and cocaine. Am J Epidemiol 155: 918-925.

Wells JE, McGee MA (2008). Violations of the usual sequence of drug initiation: prevalence and associations with the development of dependence in the New Zealand Mental Health Survey. J Stud Alcohol Drugs 69: 789-795.

Werling LL, Reed SC, Wade D, Izenwasser S (2009). Chronic nicotine alters cannabinoid-mediated locomotor activity and receptor density in periadolescent but not adult male rats. Int $J$ Dev Neurosci 27: 263-269. 